\title{
CARACTERIZAÇÃO MOLECULAR E AVALIAÇÃO DA FORMAÇÃO E TOLERÂNCIA A BIOCIDA DO BIOFILME DE Pseudomonas aeruginosa ISOLADAS DE ÁGUAS MINERAIS NATURAIS
}

\author{
MOLECULAR CHARACTERIZATION AND EVALUATION OF \\ BIOFILM FORMATION AND TOLERANCE TO THE BIOFILM OF \\ Pseudomonas aeruginosa ISOLATED FROM NATURAL MINERAL \\ WATERS
}

\section{CARACTERIZACIÓN MOLECULAR Y EVALUACIÓN DE LA FORMACIÓN Y TOLERANCIA AL BIOPELÍCULA DE Pseudomonas aeruginosa AISLADO DE AGUAS MINERALES NATURALES}

Luiza Vasconcellos

https://orcid.org/0000-0002-0849-6851

Laboratório de Microbiologia de Alimentos e

Saneantes, INCQS/Fiocruz,

Rio de Janeiro, RJ, Brasil

luiza.vasconcellos@msn.com

Cátia Aparecida Chaia Miranda https://0000-0002-8917-1249

Laboratório de Pesquisa Médica Interdisciplinar, IOC/Fiocruz Rio de Janeiro, RJ, Brasil catia.chaia@ioc.fiocruz.br

Paula Vasconcelos Costa https://orcid.org/0000-0002-1297-2136 Laboratório de Microbiologia de Alimentos e Saneantes, INCQS/Fiocruz,

Rio de Janeiro, RJ, Brasil paulavasconcelosc@gmail.com

Ingrid Camelo da Silva

https://orcid.org/0000-0002-4305-1997

Laboratório de Microbiologia de Alimentos e Saneantes, INCQS/Fiocruz, Rio de Janeiro, RJ, Brasil ingridcs@id.uff.br
Célia Maria Carvalho Pereira Araújo

Romão

https://orcid.org/0000-0002-2980-0760

Laboratório de Microbiologia de Alimentos e Saneantes, INCQS/Fiocruz, Rio de Janeiro, RJ, Brasil celia.romao@incqs.fiocruz.br

Marcelo Luiz Lima Brandão https://orcid.org/0000-0003-1121-7312 Laboratório de Controle Microbiológico,

Bio-Manguinhos/Fiocruz

Rio de Janeiro, RJ, Brasil $\underline{\text { marcelo.brandao@bio.fiocruz.br }}$

Submetido em: 22/08/2020

Aprovado em: 22/10/2020

Rev. Cient. UBM, Barra Mansa, v. 23,n. 44, 1 sem. 2021. e-ISSN 1516-4071 

VASCONCELLOS, L.; MIRANDA, C. A. C.; COSTA, P. V.; SILVA, I. C.; ROMÃO, C. M. C. P. A.;

BRANDÃO, M. L. L. Caracterização molecular e avaliação da formação e tolerância a biocida do biofilme de pseudomonas aeruginosa isoladas de águas minerais naturais. R. Científica UBM - Barra Mansa (RJ), ano XXVI, v. 23, n. 44, 1. Sem. 2021 p. 193-205.

ISSN 1516-4071

\section{RESUMO:}

Pseudomonas aeruginosa é um patógeno oportunista associado a doenças transmitidas por águas e, possui a capacidade de formar biofilme em superfícies. Neste estudo, seis cepas de $P$. aeruginosa isoladas de águas minerais naturais em embalagens reutilizáveis de $20 \mathrm{~L}$ foram submetidas à caracterização molecular por ERIC-PCR e avaliadas quanto à formação de biofilme. O ERIC-PCR revelou que as seis cepas apresentaram perfis genotípicos distintos. Nenhuma cepa apresentou formação de biofilme na matriz aço inox. Na matriz poliestireno houve formação de biofilme e a exposição ao hipoclorito de sódio a nas concentrações de $1 \%$ e $2 \%$ eliminou o biofilme formado. Contudo, na concentração $0,02 \%$ o biofilme formado não foi eliminado mesmo após 60 min de contato. O consumo de águas minerais contaminadas por $P$. aeruginosa e a possibilidade de formação de biofilmes em bebedouros de plástico podem representar um risco para indivíduos pertencentes ao grupo de risco, como grávidas, imunossuprimidos e idosos.

Palavras-Chave: Pseudomonas aeruginosa. Água mineral. Biofilme. Sanitizante.

\section{ABSTRACT:}

Pseudomonas aeruginosa is an opportunistic pathogen associated with waterborne diseases and has the ability to form biofilms on surfaces. In this study, six samples of $P$. aeruginosa isolated from mineral waters in $20 \mathrm{~L}$ mineral water returnerd plastic bottled were subjected to molecular characterization by ERIC-PCR and evaluating biofilm formation. ERIC-PCR revealed that six strains detected distinct genetic genes. No strain shows biofilm formation in the stainless steel matrix. In the polystyrene matrix, biofilm was formed and exposure to sodium hypochlorite in the ranges of $1 \%$ and $2 \%$ eliminated the biofilm formed. However, at a concentration of $0.02 \%$ in the biofilm formed, it was not eliminated after 60 minutes of contact. The consumption of mineral waters contaminated by P. aeruginosa and the possibility of biofilm formation in plastic waterer can represent a risk for individuals belonging to the risk group, such as pregnant women, immunosuppressed and elderly people.

Keywords: Pseudomonas aeruginosa. Mineral water. Biofilm. Sanitizing.

\section{RESUMEN:}

Pseudomonas aeruginosa es un patógeno oportunista asociado con enfermedades transmitidas por el agua y tiene la capacidad de formar biopelículas en las superficies. En este estudio, seis cepas de P. aeruginosa aisladas de aguas minerales naturales en envases reutilizables de 20 litros se presentada a caracterización molecular mediante ERIC-PCR y se evaluó la formación de biopelículas. ERIC-PCR reveló que las seis cepas tenían perfiles genotípicos distintos. Ninguna deformación presentó formación de biopelícula en la matriz de acero inoxidable. En la matriz de poliestireno se formó la biopelícula y la exposición a hipoclorito de sodio en concentraciones de $1 \%$ y $2 \%$ eliminó la biopelícula formada. Sin embargo, a una concentración de $0,02 \%$, la biopelícula formada no se eliminó incluso después de 60 minutos de contacto. El consumo de aguas minerales contaminadas por P. aeruginosa y la posibilidad de formación de biopelículas en bebederos de plástico pueden representar un riesgo para las personas pertenecientes al grupo de riesgo, como mujeres embarazadas, personas inmunodeprimidas y ancianos.

Palabras claves: Pseudomonas aeruginosa. Agua mineral. Biopelícula. Higienizante. 
VASCONCELlOS, L.; MIRANDA, C. A. C.; COSTA, P. V.; SILVA, I. C.; ROMÃO, C. M. C. P. A.; BRANDÃO,

M. L. L. Caracterização molecular e avaliação da formação e tolerância a biocida do biofilme de pseudomonas aeruginosa isoladas de águas minerais naturais. R. Científica UBM - Barra Mansa (RJ), ano XXVI, v. 23, n. 44,

1 INTRODUÇÃO

1. Sem. 2021 p.193- 205.

ISSN 1516-4071

A necessidade de uma maior ingestão de água aumenta em todas as condições patológicas em que ocorre uma maior perda hídrica, como nos quadros de diarreia, vômito, hiperpirexia e suor abundante (PETRACCIA et al., 2006). A água mineral é frequentemente recomendada para idosos e pacientes com deficiências no sistema imunológico. Logo, o consumo de águas minerais contaminadas pode representar risco para este grupo mais susceptível (MARKLT, 2009).

No Brasil, dados do Ministério da Saúde do período de 2009 a 2018, reportam 8.608 casos de surtos de doenças transmitidas por alimentos (DTAs). Destes, a fonte de contaminação em 2.350 dos surtos foi registrada, sendo a água identificada como a fonte em $496(21,1 \%)$ casos (BRASIL, 2019a).

Em 2019, a Agência Nacional de Vigilância Sanitária (Anvisa) revisou os padrões microbiológicos para alimentos, que incluiu as águas envasadas para consumo humano (BRASIL, 2019b). Para água mineral natural, um dos critérios preconizados é a ausência de $P$. aeruginosa em $250 \mathrm{~mL}$ de água (BRASIL, 2019c).

$P$. aeruginosa é um patógeno oportunista que está frequentemente associado a casos de doenças transmitidas por águas (WINGENDER; FLEMMING, 2011; PEDROSA et al., 2014; CASKEY S, et al., 2018). É considerado um microrganismo saprófito que se encontra difundido na natureza, particularmente em ambientes úmidos, como a água e o solo. São classificados como bastonetes Gram-negativos, aeróbios estritos, reduzem o nitrato, são catalase e oxidase positivos e a faixa decrescimento ótimo ocorre é entre 37 a $42{ }^{\circ} \mathrm{C}$ (MURRAY, 2016). Possui capacidade de sobreviver em materiais e superfícies inertes, e por conta da sua resistência antimicrobiana frequente, tem se tornado um importante patógeno nosocomial (DUBOIS et al., 2001; FURTADO et al., 2009; LINCOPAM, TRABULSI, 2011; TUON et al., 2012; CHATTERJEE et al., 2016; MORADALI et al., 2017; PANG et al., 2019).

Estudos no Brasil relataram a ocorrência de infecções nosocomiais por $P$. aeruginosa com taxa de mortalidade de 49\% (FURTADO et al., 2009; TUON et al., 2012). Concomitante a isso, dados da literatura demonstram que as águas minerais comercializadas em embalagens plástico-garrafão de $20 \mathrm{~L}$ apresentam alto índice de contaminação microbiológica, sendo $P$. aeruginosa uma das bactérias mais ocorrentes em amostras contaminadas (SANT'ANA et al., 2003; BERNARDO, 2009; BRANDÃO et al., 2012; PEDROSA et al., 2014; LUZ et al., 2020). Sua presença pode estar está associada à sua possível presença natural na microbiota da água 
VASCONCELlOS, L.; MIRANDA, C. A. C.; COSTA, P. V.; SILVA, I. C.; ROMÃO, C. M. C. P. A.; BRANDÃO, M. L. L. Caracterização molecular e avaliação da formação e tolerância a biocida do biofilme de pseudomonas aeruginosa isoladas de águas minerais naturais. R. Científica UBM - Barra Mansa (RJ), ano XXVI, v. 23, n. 44, 1 . Sem. 2021 p. 193-205.

ISSN 1516-4071

que é retirada diretamente da fonte (KIM; FENG, 2001) e à característica dessa bactéria de formar biofilmes em equipamentos e embalagens plásticas (BERNARDO, 2009; LINCOPAN; TRABULSI, 2011; PEDROSA et al., 2014; LUZ, et al., 2020).

Bernardo (2009), Pedrosa e colaboradores (2014) e Luz e colaboradores (2020) demostraram que cepas de $P$. aeruginosa isoladas de águas minerais naturais podem formar biofilme em matrizes de poliestireno. Esses resultados indicaram que a formação de biofilme em embalagens reutilizáveis de $20 \mathrm{~L}$ pode ser um problema na indústria caso a limpeza e desinfecção dessas embalagens não seja eficaz na eliminação do biofilme. Contudo, a realização de estudos relativos à formação de biofilme em outras superfícies, como por exemplo o aço inox que é o material mais comuns de maquinários industriais utilizados nas etapas de envase de águas minerais (BRASIL, 2006), é importante para elucidar se a formação de biofilme nestas superfícies também pode atuar como uma fonte de contaminação nas indústrias de águas minerais.

O objetivo deste estudo foi tipificar e avaliar a tolerância do biofilme produzido por cepas de $P$. aeruginosa isoladas a partir de águas minerais naturais comercializadas em embalagens retornáveis de $20 \mathrm{~L}$.

\section{MATERIAIS E MÉTODOS}

\subsection{CEPAS E CONDIÇÕES DE CULTIVO}

Seis (6) cepas de P. aeruginosa (P163, P164, P165, P166, P167 e P168) isoladas de águas minerais naturais comercializadas em embalagens retornáveis de 20 L foram avaliadas neste estudo. As cepas foram previamente identificadas, utilizando sistema Semi automatizado Vitek 2.0, com nível de confiança Excelente (97-99\%) e testadas quanto à formação de biofilme em matriz de poliestireno (LUZ et al., 2020).

A cepa de $P$. aeruginosa ATCC 27853 (INCQS 00099) foi utilizada como controle positivo nos testes e foi oriunda da Coleção de Bactérias de Referência em Vigilância Sanitária (CBRVS) do INCQS/Fiocruz.

As cepas foram criopreservadas em caldo infusão cérebro-coração (BHI; Merck, Alemanha) contendo $20 \%$ de glicerol (Merck, Alemanha) e mantidas a $-70{ }^{\circ} \mathrm{C}$. Para realização 
VASCONCEllos, L.; MIRANDA, C. A. C.; COSTA, P. V.; SILVA, I. C.; ROMÃO, C. M. C. P. A.; BRANDÃO,

M. L. L. Caracterização molecular e avaliação da formação e tolerância a biocida do biofilme de pseudomonas aeruginosa isoladas de águas minerais naturais. R. Científica UBM - Barra Mansa (RJ), ano XXVI, v. 23, n. 44, 1. Sem. 2021 p.193- 205.

ISSN 1516-4071

dos experimentos, uma alçada desta cultura foi semeada em caldo BHI e em ágar nutriente (Merck, Alemanha) e incubados a $35 \pm 2{ }^{\circ} \mathrm{C} / 24 \mathrm{~h}$.

\subsection{CARACTERIZAÇÃO MOLECULAR POR ENTEROBACTERIAL REPETITIVE} INTERGENIC CONSENSUS POLYMERASE CHAIN REACTION (ERIC-PCR)

As cepas de $P$. aeruginosa foram submetidos à técnica do Enterobacterial Repetitive Intergenic Consensus Polymerase Chain Reaction (ERIC-PCR) segundo descrito por Versalovic e colaboradores (1991), utilizando-se o iniciador ERIC-2 (5'AAGTAAGTGACTGGGGTGAGCG-3'). A extração de DNA foi realizada com o kit comercial Dneasy Blood \& Tissue (Qiagen, EUA) de acordo com as instruções do fabricante. As reações em cadeia pela polimerase (PCRs) foram realizadas em aparelho SimpliAmp ThermalCycler (Applied Biosystems, Singapore). Os produtos amplificados foram submetidos à eletroforese em gel de agarose a 1,5\% a 60 V/80 min com a aplicação de corante fluorescente de ácidos nucléicos ultrassensível (GelRed®, Thermo Fischer, EUA). Para visualização da amplificação, utilizou-se sistema de fotodocumentação L-PIX Touch (LOCCUS, Brasil). Os produtos amplificados foram purificados utilizando-se kit comercial (Quick PCR Purification Kit, Invitrogen, USA) e a concentração e a qualidade do DNA foram avaliadas em espectrofotômetro NanoDrop-2000c (ThermoScientific, EUA). Os produtos da amplificação foram analisados por eletroforese em gel de 1,5\% de agarose, utilizando o corante GelRed, em tampão TBE $0,5 \mathrm{X}$ por $90 \mathrm{~min}$ a $60 \mathrm{~V}$. Como marcador de peso molecular foi utilizado o peso 1 kb plus DNA ladder (Invitrogen, EUA). O gel foi fotografado e analisado utilizando-se sistema de fotodocumentação L-PIX Touch. Os padrões de bandas foram analisados com uso do Programa BioNumerics versão 6.6 (Applied Maths, Kortrijk, Bélgica). O dendograma foi construído com índice de Dice e o método "unweighted Pair Group Method with Arithmetic average" (UPGMA) (VAN BELKUM et al., 2007).

\section{2 .3 PESQUISA DE FORMAÇÃO DE BIOFILME EM MATRIZ AÇO INOX}

Tendo em vista que as cepas de $P$. aeruginosa apresentaram formação de biofilme na matriz de poliestireno (LUZ, et al., 2020), neste estudo foi avaliado a formação de biofilme na matriz aço inox.

Uma colônia isolada foi semeada em dois tubos contendo $5,0 \mathrm{~mL}$ de caldo infusão cérebro-coração (BHI) (Merck, Alemanha) incubados sob agitação de 150 rpm (Orbit-Shaker, 
VASCONCELlOS, L.; MIRANDA, C. A. C.; COSTA, P. V.; SILVA, I. C.; ROMÃO, C. M. C. P. A.; BRANDÃO, M. L. L. Caracterização molecular e avaliação da formação e tolerância a biocida do biofilme de pseudomonas aeruginosa isoladas de águas minerais naturais. R. Científica UBM - Barra Mansa (RJ), ano XXVI, v. 23, n. 44, 1 . Sem. 2021 p. 193-205.

ISSN 1516-4071

Lab-Line, EUA) a $36 \pm 2{ }^{\circ} \mathrm{C}$ por $24 \mathrm{~h}$. Após a incubação, um tubo de caldo BHI foi utilizado para inoculação de $2,0 \mathrm{~mL}$ do crescimento celular em dois tubos 38 x $250 \mathrm{~mm}$ contendo um cilindro de aço inox. $\mathrm{O}$ segundo tubo da mesma cepa foi centrifugado a $7.500 \mathrm{rpm} / 10 \mathrm{~min}$ (Eppendorf 5804-R, A-4-44, Alemanha), o sobrenadante foi descartado, e o sedimento ressuspenso em 5,0 $\mathrm{mL}$ de água mineral natural estéril (autoclavada a $121^{\circ} \mathrm{C} / 15 \mathrm{~min}$ ). Dois microlitros dessa suspensão foram inoculados em dois tubos contendo um cilindro de aço inox de aproximadamente $15 \mathrm{~mm}$ cada. A cepa de P. aeruginosa ATCC 27853 (INCQS 00099) foi utilizada como $\mathrm{CP}$. Caldo BHI sem crescimento e uma água mineral natural estéril foram utilizados como CNs. Um tubo foi incubado a $25 \pm 2{ }^{\circ} \mathrm{C}$ e o outro a $36 \pm 2{ }^{\circ} \mathrm{C}$ por $48 \mathrm{~h}$.

Para leitura, cada cilindro de aço inox foi lavado por cinco vezes com água destilada e mantida a temperatura ambiente durante $45 \mathrm{~min}$. A seguir, foram adicionados $2,0 \mathrm{~mL}$ de solução de cristal violeta 0,41\% (Merck, Alemanha) e os tubos foram mantidos em temperatura ambiente por $45 \mathrm{~min}$. A lavagem foi realizada novamente por cinco vezes em água destilada, e o cilindro transferido para um tubo novo da mesma dimensão e mantido a temperatura ambiente por $45 \mathrm{~min}$.

Em seguida, foram adicionados 2,0 mL de etanol a 96\% (Merck, Alemanha). Após 10 min, $150 \mu \mathrm{L}$ do conteúdo de cada tubo foram transferidos para microplacas de 96 poços e foi realizada a leitura da densidade óptica (D.O.) em aparelho espectrofotômetro (Biomérieux, Reader 270, França) em comprimento de onda de $600 \mathrm{~nm}$.

A interpretação dos resultados foi realizada pela média das nove leituras dos três experimentos independentes e foram classificados da seguinte forma: não aderente (NA), fracamente aderente (FA), moderadamente aderente (MA) e fortemente aderente (FMA), segundo critérios descritos por Stepanovic e colaboradores (2007).

\subsection{AÇO INOX AVALIAÇÃO DA ATIVIDADE ANTIBIOFILME DO HIPOCLORITO} DE SÓDIO FRENTE À FORMAÇÃO DE BIOFILME DOS ISOLADOS

A atividade antibiofilme do hipoclorito de sódio foi analisada na matriz de poliestireno utilizando o protocolo descrito por Silva (2019).

Foi adquirido um produto à base de hipoclorito de sódio (Super globo, Brasil), obtido no comércio do município do Rio de Janeiro e testado quanto ao teor de cloro ativo, de acordo 
VASCONCELlOS, L.; MIRANDA, C. A. C.; COSTA, P. V.; SILVA, I. C.; ROMÃO, C. M. C. P. A.; BRANDÃO,

M. L. L. Caracterização molecular e avaliação da formação e tolerância a biocida do biofilme de pseudomonas

aeruginosa isoladas de águas minerais naturais. R. Científica UBM - Barra Mansa (RJ), ano XXVI, v. 23, n. 44, 1. Sem. 2021 p.193- 205.

com o declarado no rótulo pelo fabricanteIs como referência a RDC n 110/2016 (BRASIL, 2016), sendo considerado satisfatório.

Previamente às análises, o produto foi diluído utilizando-se água mineral estéril para adequação às seguintes concentrações:

- Simulação de desinfecção geral (superfícies fixas, pisos, paredes, etc...): 2\%;

- Simulação de desinfecção de alimentos: 1\%;

- Simulação de desinfecção de bebedouros: 0,02\%.

Uma colônia isolada de cada cepa foi semeada em dois tubos contendo $3,0 \mathrm{~mL}$ de caldo BHI e incubados sob agitação de $150 \mathrm{rpm}$ a $36 \pm 2{ }^{\circ} \mathrm{C}$ por $24 \mathrm{~h}$. Após o período de incubação, um tubo de BHI foi utilizado para a inoculação de $200 \mu \mathrm{L}$ do crescimento bacteriano, em triplicata, em duas microplacas de poliestireno contendo 96 orifícios com fundo chato (Microtes ${ }^{\mathrm{TM}}$ Falcon, EUA). O outro tubo de BHI foi centrifugado (Eppendorf 5804-R, A4-44, Alemanha) a $7.500 \mathrm{rpm}$ por10 min. O sobrenadante foi descartado e o precipitado ressuspendido com 1,5 mL de água mineral estéril. Duzentos microlitros dessa suspensão foram inoculados, em triplicata, nas duas microplacas. A cepa de $P$. aeruginosa ATCC 27853 (INCQS 00099) foi utilizada como controle positivo (CP) e o caldo BHI e a água mineral estéril foram utilizados como controles negativos (CN). Uma placa foi incubada na temperatura de $25 \pm 2{ }^{\circ} \mathrm{C}$ e a outra a $36 \pm 2{ }^{\circ} \mathrm{C}$. Após o período de 48 h de incubação, o conteúdo de cada poço foi aspirado. Os biofilmes formados pelas cepas foram expostos, em triplicata, a soluções de hipoclorito de sódio nas seguintes concentrações e tempos de exposição: 0,02\% por 10, 30 e 60 min; $1 \%$ por $10 \mathrm{~min}$; e $2 \%$ por $10 \mathrm{~min}$. As placas foram lavadas cinco vezes em água destilada e foram mantidas à temperatura ambiente até a completa secagem.

A seguir foram adicionados $200 \mu \mathrm{L}$ de solução cristal violeta (Merck, Alemanha) $0,41 \%$ em cada poço nas microplacas e estas foram mantidas a temperatura ambiente por 45 min. Os poços foram aspirados e as placas foram lavadas por cinco vezes em água destilada e mantidas em temperatura ambiente até a completa secagem. Em seguida, foram adicionados $200 \mu \mathrm{L}$ de etanol absoluto (Merck, Alemanha) e as placas foram mantidas sob agitação a 500 rpm em aparelho agitador de placas. Após $10 \mathrm{~min}, 150 \mu \mathrm{L}$ do conteúdo de cada poço foram transferidos para novas microplacas e foi realizada a leitura da densidade óptica (D.O.) em aparelho espectrofotômetro (Biomérieux, Reader 270, França) em comprimento de onda de 600 nm. A interpretação dos resultados foi realizada conforme descrito no item 3. 
VASCONCELlOS, L.; MIRANDA, C. A. C.; COSTA, P. V.; SILVA, I. C.; ROMÃO, C. M. C. P. A.; BRANDÃO, M. L. L. Caracterização molecular e avaliação da formação e tolerância a biocida do biofilme de pseudomonas aeruginosa isoladas de águas minerais naturais. R. Científica UBM - Barra Mansa (RJ), ano XXVI, v. 23, n. 44, 1 . Sem. 2021 p. 193-205.

ISSN 1516-4071

\section{RESULTADOS E DISCUSSÃO}

A tipificação molecular pela técnica da ERIC-PCR das seis cepas de $P$. aeruginosa está descrita na Figura 1. O perfil molecular, projetado a partir do dendograma, demonstra que todas as cepas apresentaram um perfil filogenético distinto (classificados de A-F), com similaridade $\leq 80 \%$ entre as cepas. Esse resultado corroborou com o relatado por Luz et al. (2020), que ao avaliaram as cepas pela técnica do Multi Locus Sequence Typing (MLST) observaram que todas as cepas foram classificadas em diferentes tipos sequenciais.

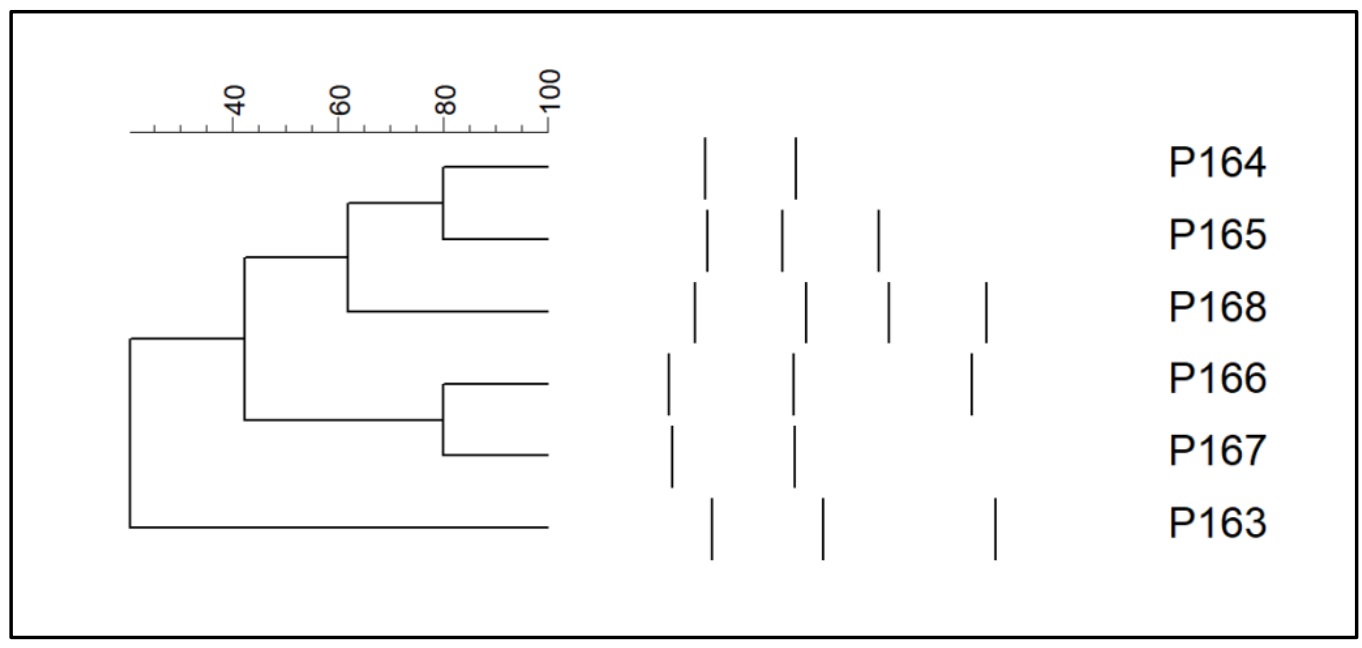

Figura 1. Perfil de bandas representativo dos perfis dos isolados de P. aeruginosa por ERIC-PCR.

Os resultados em relação a formação de biofilme na matriz aço inox estão apresentados na Tabela 1. Todas as cepas foram consideradas como NA ou FA em ambas as matrizes em ambas as temperaturas estudadas. $\mathrm{O}$ caldo $\mathrm{BHI}$ é um caldo rico em nutrientes, favorecendo o crescimento dos micro-organismos. A água mineral foi utilizada como parâmetro de crescimento justamente onde as cepas foram previamente isoladas neste estudo. A temperatura de $25 \pm 2{ }^{\circ} \mathrm{C}$ simulou a temperatura ambiente, que seria a temperatura em que normalmente os processos ocorreriam na indústria. A temperatura de $36 \pm 2{ }^{\circ} \mathrm{C}$ simulou a temperatura ótima de crescimento de $P$. aeruginosa. Como a formação de biofilme na matriz inox não foi identificada, mesmo no caldo BHI e na temperatura ótima de crescimento, esses resultados indicam que a formação de biofilme nas embalagens reutilizáveis parece ser a causa mais 
VASCONCEllos, L.; MIRANDA, C. A. C.; COSTA, P. V.; SILVA, I. C.; ROMÃO, C. M. C. P. A.; BRANDÃO,

M. L. L. Caracterização molecular e avaliação da formação e tolerância a biocida do biofilme de pseudomonas aeruginosa isoladas de águas minerais naturais. R. Científica UBM - Barra Mansa (RJ), ano XXVI, v. 23, n. 44, 1. Sem. 2021 p.193- 205.

provável da contaminação e persistênciaIs\$d P16A comercializadas em embalagens reutilizáveis de $20 \mathrm{~L}$.

Tabela 1. Formação de Biofilme em matriz poliestireno e matriz aço inox.

\begin{tabular}{cccccc}
\hline \multirow{2}{*}{ Cepa } & $\begin{array}{c}\text { Perfil do ERIC- } \\
\text { PCR }\end{array}$ & \multicolumn{4}{c}{ Produção de Biofilme em matriz aço inox } \\
\cline { 3 - 6 } & & Caldo infusão cérebro-coração & Água mineral natural estéril \\
\cline { 2 - 6 } & A & FA & FA & FA & NA \\
P163 & B & FA & FA & FA & NA \\
P164 & C & FA & FA & FA & NA \\
P165 & D & FA & FA & NA & NA \\
P166 & E & FA & NA & NA & NA \\
P167 & F & FA & FA & NA & NA \\
P168 & &
\end{tabular}

NA - não aderente, FA - fracamente aderente, MA - moderadamente aderente, FMA - fortemente aderente.

A avaliação atividade antibiofilme do hipoclorito de sódio frente ao biofilme formado pelos isolados está apresentando na Tabela 2. Na matriz de poliestireno, no caldo BHI, todas as cepas de $P$. aeruginosa $(\mathrm{n}=6)$ foram capazes de produzir biofilme (Tabela 2) e foram consideradas moderadamente ou fortemente aderentes em ambas às temperaturas estudadas (25 e $\left.36^{\circ} \mathrm{C}\right)$

Já na água mineral natural, somente a cepa P164 foi capaz de produzir biofilme moderado na temperatura de $(25 \pm 2){ }^{\circ} \mathrm{C}$. Esses resultados também foram observados por Pedrosa e colaboradores (2014) que relataram que as cepas de $P$. aeruginosa produzem mais biofilme em matriz BHI do que em água mineral natural. No entanto, Silva e colaboradores, (2008) avaliaram 10 isolados de $P$. aeruginosa em água mineral e observaram que nenhuma cepa foi capaz de aderir ao material PET. A composição do meio é provavelmente o fator mais importante que influencia a capacidade das bactérias de produzir biofilme sob condições in vitro (STEPANOVIC et al., 2007).

A exposição ao hipoclorito de sódio a 0,02\% não eliminou o biofilme nem mesmo após 60 min de contanto, como apresentado na Tabela 2 . Já nas concentrações de 1 e $2 \%$ o hipoclorito de sódio eliminou o biofilme formado pelas cepas.

De acordo com Manual do Ministério de Saúde - Processamento de Artigos e Superfícies em Estabelecimentos de Saúde (BRASIL, 1994), o uso de hipoclorito de sódio na concentração de $0,02 \%$ durante 60 min é indicado para desinfecção de bebedouros que são comumente utilizados para acoplar as embalagens de $20 \mathrm{~L}$ de águas minerais. Dessa forma, os resultados do presente estudo indicam que caso o biofilme tenha sido formado nestes bebedouros, esse tratamento parece não ser suficiente para eliminar a contaminação por estes 
VASCONCELLOS, L.; MIRANDA, C. A. C.; COSTA, P. V.; SILVA, I. C.; ROMÃO, C. M. C. P. A.; BRANDÃO, M. L. L. Caracterização molecular e avaliação da formação e tolerância a biocida do biofilme de pseudomonas aeruginosa isoladas de águas minerais naturais. R. Científica UBM - Barra Mansa (RJ), ano XXVI, v. 23, n. 44, 1. Sem. 2021 p. 193-205.

ISSN 1516-4071

patógenos. Os experimentos da avaliação antibiofilme em matriz aço inox não foram realizados, já que, de acordo com os resultados obtidos, as cepas não apresentaram formação de biofilme nesta matriz (Tabela 1$)$.

Tabela 2. Avaliação da tolerância dos biofilmes das cepas de $P$. aeruginosa em matriz poliestireno frente a diferentes concentrações de hipoclorito de sódio em tempos de contato distintos.

\begin{tabular}{|c|c|c|c|c|c|c|c|}
\hline \multirow{3}{*}{ Cepa } & \multirow{3}{*}{$\begin{array}{c}\text { Concentração de } \\
\text { hipoclorito de sódio }\end{array}$} & \multicolumn{6}{|c|}{ Temperatura/Tempo de exposição } \\
\hline & & \multicolumn{3}{|c|}{$36 \pm 1^{\circ} \mathrm{C}$} & \multicolumn{3}{|c|}{$25 \pm 2^{\circ} \mathrm{C}$} \\
\hline & & $10 \mathrm{~min}$ & $30 \mathrm{~min}$ & $60 \mathrm{~min}$ & $10 \mathrm{~min}$ & $30 \mathrm{~min}$ & $60 \mathrm{~min}$ \\
\hline \multirow[t]{4}{*}{ P163 } & Sem adição & FMA & FMA & FMA & FMA & FMA & FMA \\
\hline & $0,02 \%$ & MA & MA & FMA & MA & MA & FMA \\
\hline & $1 \%$ & NA & - & - & NA & - & - \\
\hline & $2 \%$ & NA & - & - & FA & - & - \\
\hline \multirow[t]{4}{*}{ P164 } & Sem adição & FMA & FMA & FMA & FMA & FMA & FMA \\
\hline & $0,02 \%$ & FMA & FMA & FMA & FMA & FMA & FMA \\
\hline & $1 \%$ & NA & - & - & NA & - & - \\
\hline & $2 \%$ & NA & - & - & NA & - & - \\
\hline \multirow[t]{4}{*}{ P165 } & Sem adição & FMA & FMA & FMA & FMA & MA & MA \\
\hline & $0,02 \%$ & FA & FA & FA & FA & FA & FA \\
\hline & $1 \%$ & NA & - & - & NA & - & - \\
\hline & $2 \%$ & NA & - & - & FA & - & - \\
\hline \multirow[t]{4}{*}{ P166 } & Sem adição & FMA & FMA & FMA & MA & FMA & FMA \\
\hline & $0,02 \%$ & MA & FMA & FMA & FMA & FMA & FMA \\
\hline & $1 \%$ & NA & - & - & NA & - & - \\
\hline & $2 \%$ & NA & - & - & NA & - & - \\
\hline \multirow[t]{4}{*}{ P167 } & Sem adição & FMA & FMA & FMA & FMA & FMA & FMA \\
\hline & $0,02 \%$ & FMA & FMA & FMA & FMA & FMA & FMA \\
\hline & $1 \%$ & NA & - & - & NA & - & - \\
\hline & $2 \%$ & NA & - & - & FA & - & - \\
\hline \multirow[t]{4}{*}{ P168 } & Sem adição & FMA & FMA & FMA & FMA & MA & FMA \\
\hline & $0,02 \%$ & FA & MA & MA & MA & MA & MA \\
\hline & $1 \%$ & NA & - & - & NA & - & - \\
\hline & $2 \%$ & NA & - & - & FA & - & - \\
\hline$P$. & Sem adição & FMA & FMA & FMA & FMA & MA & FMA \\
\hline aerugino & $0,02 \%$ & FA & MA & MA & MA & MA & MA \\
\hline sa & $1 \%$ & NA & - & - & NA & - & - \\
\hline $\begin{array}{c}\text { ATCC } \\
27853\end{array}$ & $2 \%$ & NA & - & - & FA & - & - \\
\hline
\end{tabular}

NA - não aderente, FA - fracamente aderente, MA - moderadamente aderente, FMA - fortemente aderente. 'NA' Não realizado. 
VASCONCEllos, L.; MIRANDA, C. A. C.; COSTA, P. V.; SILVA, I. C.; ROMÃO, C. M. C. P. A.; BRANDÃO,

M. L. L. Caracterização molecular e avaliação da formação e tolerância a biocida do biofilme de pseudomonas aeruginosa isoladas de águas minerais naturais. R. Científica UBM - Barra Mansa (RJ), ano XXVI, v. 23, n. 44, 1. Sem. 2021 p.193- 205.

ISSN 1516-4071

\section{CONSIDERAÇÕES FINAIS}

Cepas de $P$. aeruginosa isoladas de águas minerais não foram capazes de produzir biofilme em matriz aço inox, indicando que biofilmes em equipamentos parecem não ser a principal fonte de contaminação por estes microrganismos nas indústrias.

No presente trabalho, a exposição ao hipoclorito de sódio a $0,02 \%$ não eliminou o biofilme formado pelos isolados de $P$. aeruginosa em matriz poliestireno nem mesmo após 60 min de contato. Dessa forma, os resultados indicam que caso o biofilme tenha sido formado em utilitários (como no caso dos bebedouros de plástico), que são desinfetados nessas concentrações, esse tratamento parece não ser suficiente para eliminar o biofilme formado por estes patógenos. Considerando a ocorrência de $P$. aeruginosa em águas minerais naturais e, a sua capacidade de formar biofilme em embalagens plásticas, o consumo destas por indivíduos pertencentes ao grupo de risco é uma preocupação.

\section{REFERÊNCIAS}

BRANDAO, M. L. L., et al. Comparação das técnicas do número mais provável (NMP) e de filtração em membrana na avaliação da qualidade microbiológica de água mineral natural. Rev Inst Adolfo Lutz, v. 71, n. 1, p. 32-9, 2012.

BRASIL. Ministério da Saúde. Coordenação de Controle de Infecção Hospitalar. Processamento de Artigos e Superfícies em Estabelecimentos de Saúde. 2. ed. Brasília, 1994.

BRASIL. Ministério da Saúde. Resolução de Diretoria Colegiada n. ${ }^{\circ} 173$, de 13 de setembro de 2006. Regulamento Técnico de Boas Práticas para Industrialização e Comercialização de Águas Minerais Naturais e Águas Minerais. Diário Oficial da União, Brasília, DF, 10 set. 2006.

BRASIL. Ministério da Saúde. Resolução RDC nº 110, de 6 de setembro de 2016. Dispõe sobre regulamento técnico para produtos saneantes categorizados como água sanitária e dá outras providências. Diário Oficial [da] República Federativa do Brasil. Brasília, DF, 08 de setembro de 2016.

BRASIL. Ministério da Saúde. Secretaria de Vigilância em saúde. Surtos de doenças transmitidas por alimentos no Brasil [Internet]. Brasília, DF: Ministério da Saúde; 2019a [acesso 6 jul 2020]. Disponível em: 
VASCONCELlOS, L.; MIRANDA, C. A. C.; COSTA, P. V.; SILVA, I. C.; ROMÃO, C. M. C. P. A.; BRANDÃO, M. L. L. Caracterização molecular e avaliação da formação e tolerância a biocida do biofilme de pseudomonas aeruginosa isoladas de águas minerais naturais. R. Científica UBM - Barra Mansa (RJ), ano XXVI, v. 23, n. 44, 1 . Sem. 2021 p. 193-205.

ISSN 1516-4071

http://portalarquivos2.saude.gov.br/images/pdf/2019/fevereiro/15/Apresenta----o-SurtosDTA---Fevereiro-2019.pdf

BRASIL. Agência Nacional de Vigilância Sanitária. Instrução Normativa - IN no 331 de 23 de dezembro de 2019. Dispõe sobre os padrões microbiológicos de alimentos e sua aplicação. Diário Oficial [da] República Federativa do Brasil. Brasília, DF, 2019 b.

BRASIL. Agência Nacional de Vigilância Sanitária. Instrução Normativa - IN nº 60 de 23 de dezembro de 2019. Estabelece as listas de padrões microbiológicos para alimentos. Diário Oficial [da] República Federativa do Brasil. Brasília, DF, 2019c.

BERNARDO, S. P. C. Avaliação da Suscetibilidade a Antimicrobianos e Formação de Biofilmes em Pseudomonas aeruginosa Isoladas de Água Mineral. Rio de Janeiro: INCQS/FIOCRUZ, 2009. xv, 46 p., il., tab. Dissertação (Mestrado) - Fundação Oswaldo Cruz, Instituto Nacional de Controle de Qualidade em Saúde, Programa de Pós-Graduação em Vigilância Sanitária, Rio de Janeiro, 2009.

CHATTERJEE, M. et al. Antibiotic resistance in Pseudomonas aeruginosa and alternative therapeutic options. Int J Med Microbiol. v. 306, n 1, p. 48-58, 2016.

DUBOIS, V. et al. Nosocomial outbreak due to a multiresistant strain of Pseudomonas aeruginosa P12: efficacy of Cefepime - Amikacin therapy and analysis of $\beta$-lactam resistance. J Clin Microbiol, v. 39, p. 2072-2078, 2001.

CASKEY S, et al. Occurrence of Pseudomonas aeruginosa in waters: implications for patients with cystic fibrosis (CF). Lett Appl Microbiol. v.66, n.6, p.537-541, 2018.

FURTADO, G. H., et al. Imipenem-resistant Pseudomonas aeruginosa infection at a medicalsurgical intensive care unit: risk factors and mortality. J Crit Care. v. 24, n.4, p.625.e9-14, 2009.

KIM, H.; FENG, P. Bottled water. In: DOWNES, F. P.; ITO, K.; AMERICAN PUBLIC HEALTH ASSOCIATION. Compendium of methods of examination of foods. 4. ed. Washington: APHA, p. 573-576, 2001.

LINCOPAM, e TRABULSI. Pseudomonas aeruginosa multirresistente: um problema endêmico no Brasil. J Bras Patol Med Lab. v. 47, n. 4, p. 409-420, 2011.

LUZ, I. S. et al. Assessment of the microbiological quality of natural mineral waters according to the manufacturing time of $20 \mathrm{~L}$ returnable packs in Brazil. FEMS Microbiology Letters, 2020. In Press

MURRAY, P. R.; ROSENTHAL, K.S.; PFALLER, M. A. MEDICAL MICROBIOLOGY. JMI Laboratories. 8th edition, 2016.

MORADALI, M. F.; GHODS, S.; REHM, B. H. Pseudomonas aeruginosa Lifestyle: A Paradigm for Adaptation, Survival, and Persistence. Front Cell Infect Microbiol. v. 7, p. 39, 2017. 
VASCONCEllos, L.; MIRANDA, C. A. C.; COSTA, P. V.; SILVA, I. C.; ROMÃO, C. M. C. P. A.; BRANDÃO,

M. L. L. Caracterização molecular e avaliação da formação e tolerância a biocida do biofilme de pseudomonas aeruginosa isoladas de águas minerais naturais. R. Científica UBM - Barra Mansa (RJ), ano XXVI, v. 23, n. 44, 1. Sem. 2021 p.193- 205.

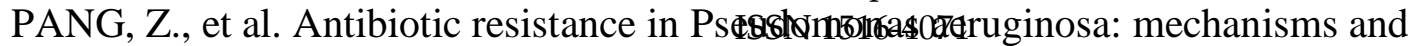
alternative therapeutic strategies. Biotechnol Adv, v. 37, n. 1, p.177-192, 2019.

PEDROSA, A. P., et al. Pesquisa de fatores de virulência em Pseudomonas aeruginosa isoladas de águas minerais naturais. Rev Ambient Água, v. 9, n. 2, p. 313-324, 2014.

PETRACCIA, L. et al. Water, mineral waters and health. Clin Nutr. v. 25, n. 3, p.377-385, 2006.

SANT'ANA, A. et al. Qualidade microbiológica de águas minerais. Ciência e Tecnologia de Alimentos, Campinas, v. 23, p. 190-194, 2003.

STEPANOVIC, S. et al. Quantification of biofilm in microtiter plates: overview of testing conditions and practical recommendations for assessment of biofilm production by staphylococci. APMS, v. 115, n. 8, p 891-899, 2007.

SILVA et al. Comparison of the bacteriological quality of tap water and bottled mineral water. Int J Hyg Environ Health. v. 211, p.504-509, 2008.

SILVA, I. C. Avaliação da produção de biofilmes por cepas de L. monocytogenes isoladas de alimentos e seus perfis de tolerância à sanificantes. Rio de Janeiro: IFRJ/CMAR/CoBib, 2020. $44 \mathrm{f} ; 21 \mathrm{~cm}$. Trabalho de Conclusão de Curso (Especialização em Gestão de Segurança de Alimentos e Qualidade Nutricional) - Instituto Federal de Educação, Ciência e Tecnologia do Rio de Janeiro, 2019.

TUON, F. F., et al. Risk factors for pan-resistant Pseudomonas aeruginosa bacteremia and the adequacy of antibiotic therapy. The Brazilian journal of infectious diseases: an official publication of the Brazilian Society of Infectious Diseases, v. 16, n.4, p.351-356, 2012.

VAN BELKUM, A. et al. Guidelines for the validation and application of typing methods for use in bacterial epidemiology. Clin Microbiol Infect Dis, v. 13, p. 1-46, 2007.

VERSALOVIC, J.; KOEUTH, T.; LUPSKI, J. R. Distribution of repetitive DNA sequences in eubacterial and application to fingerprinting of bacterial genomes. Nucleic Acids Res, v. 19, p. 6823-6831, 1991.

WINGENDER, J.; FLEMMING, H. C. Biofilms in drinking water and their role as reservatoir for pathogens. International Journal of Hygiene and environmental Health, Alemanha, v. 214, n. 6, p. 417-423, 2011. 